\title{
The Evaluation and Analysis of the Eastern Regional Industrial Competitiveness Based on Factor Analysis
}

\author{
Rongping Li \\ College of Economics and Management, \\ Hebei University of Science and Technology \\ Shijiazhuang, China \\ 1965322@163.com
}

\begin{abstract}
On the basis of pinpointing the meaning of industrial competitiveness and analyzing its influence factors, we build an evaluation index system of regional industrial competitiveness constructed by three first-level indicators-- the scale of regional industrial, the efficiency of industrial enterprises and the development ability of industrial enterprise, and 11 second-level indicators. We empirically measure and analyze comprehensive competitiveness of 12 provinces and cities in eastern industrial using the factor analysis. The results show that the three factors reflecting the strength of industrial competitiveness of 12 provinces is different. Cities should adjust measures to improve their industrial competitiveness according to local conditions.
\end{abstract}

Keywords-industrial competitiveness; index system; factor analysis; the empirical analysis; conclusions and policy recommendations

\section{INTRODUCTION}

Since China's reform and opening up, differences among the provincial regional industrial competitiveness level cause a wide attention from academic circles, politics to the social from all walks of life. Many scholars use different evaluation methods to research, and discuss the industrial competitiveness, which promotes the development of the industrial competitiveness of the empirical evaluation. In the process of industrialization in our country, the eastern province is in the forefront of industrial development, so the studies of industrial competitiveness of eastern provinces and cities has become very valuable. By building an evaluation index system of competitiveness in regional industrial, we can use the factor analysis to give a scientific evaluation on industrial competitiveness of eastern provinces and cities, analyze the evaluation results, and put forward countermeasures and suggestions to improve industrial competitiveness.

\section{THE CONSTRUCTION OF EVALUATION INDEX SYSTEM OF INDUSTRIAL COMPETITIVENESS OF THE EASTERN PROVINCES AND CITIES}

\section{A. The meaning and influence factors of the industrial competitiveness}

Industrial competitiveness refers to a kind of ability that industrial enterprises in one region can use the resources to obtain benefits more effectively than competitors in the market, it can comprehensively reflect the ability, strength and the potential of the development of industrial economy. In general, the influencing factors of the industrial economy are the

\author{
Yuanjie Li \\ College of Economics and Management, \\ Hebei University of Science and Technology \\ Shijiazhuang, China \\ 854763920@qq.com
}

influencing factors of industrial competitiveness. In this paper, starting from the definition of industrial competitiveness, at the same time, referring to the relevant literature, the influence factors can be concluded the following three points [1]:
1) Regional industrial scale
2) Efficiency of industrial enterprises
3) Industrial enterprise development ability.

\section{B. The index system framework and content of industrial competitiveness evaluation of eastern provinces and cities}

According to the analysis of the influence factors of industrial competitiveness, at the same time considering targeted and systematic, operability and objectivity of the evaluation, the paper sets up an industrial competitiveness evaluation index system of the eastern provinces, and cities consisted of three first-level indicators, 11 second-level indicators, as shown in table I. 


\begin{tabular}{|c|c|}
\hline Primary indicators & Secondary indicators \\
\hline \multirow{4}{*}{ Scale of regional industrial } & 1. The number of enterprise (the number) \\
\hline & 2. Gross value of industrial output (one hundred million yuan) \\
\hline & 3. Gross assets (one hundred million yuan) \\
\hline & 4. The average number of all workers, (ten thousand) \\
\hline \multirow{4}{*}{ Efficiency of industrial enterprises } & 5. Total profit (one hundred million yuan) \\
\hline & 6. The overall Labour productivity (yuan/person) \\
\hline & 7. The market share $(\%)$ \\
\hline & 8. Product sales rate $(\%)$ \\
\hline \multirow{3}{*}{$\begin{array}{c}\text { Development ability of industrial } \\
\text { enterprise }\end{array}$} & 9. R\&D expenditure in the proportion of main business income $(\%)$ \\
\hline & 10. Full-time equivalent of R\&D personnel (man-year) \\
\hline & 11. Output of new product in the proportion of gross output in the same year $(\%)$ \\
\hline
\end{tabular}

\section{MODELING THE INDUSTRIAL COMPETITIVENESS} EVALUATION OF THE EASTERN PROVINCES AND CITIES

The purpose of evaluating the industrial competitiveness in eastern provinces and cities is to put 11 complex evaluation indexes to be classified as one of the few elements, and then to score, therefore, using factor analysis is appropriate [2].

Assuming that there are $\mathrm{n}$ samples, each sample has $\mathrm{p}$ observed variables, noted as the $\mathrm{x}_{1}, \mathrm{x}_{2}, \ldots \mathrm{x}_{\mathrm{p}}$ (for simplicity, you can set the $x_{i}$ with a mean of zero, and the variance of $1,1 \leqslant i \leqslant$ $\mathrm{p})$, We can get a linear consist of $\mathrm{k}(\mathrm{k}<\mathrm{p})$ factors, such as $\mathrm{F}_{1}$, $\mathrm{F}_{2}, \mathrm{~F}_{3}, \ldots \mathrm{F}_{\mathrm{k}}$, expressed each of the original variables:

$$
\left\{\begin{array}{c}
x_{1}=a_{11} F_{1}+a_{12} F_{2}+\cdots+a_{1 k} F_{k}+\zeta_{1} \\
x_{2}=a_{21} F_{1}+a_{22} F_{2}+\cdots+a_{2 k} F_{k}+\zeta_{2} \\
\vdots \\
X_{p}=a_{m 1} F_{1}+a_{m 2} F_{2}+\cdots+a_{p k} F_{k}+\zeta_{p}
\end{array}\right.
$$

(1) is the mathematical model of factor analysis, and also can be expressed by the matrix form:

$$
X=A F+\zeta
$$

In the formula (2), $\mathrm{F}$ called the common factor, is common factor in every expression of observations, is the unobservable, independent and theoretical variables; $\zeta$ is called special factors, which is is a particular factor owned by A vector. In the type (1), $a_{i j}$ which is in the matrix $A=\left(a_{i j}\right)$ is called the factor loading, the greater the absolute value of $a_{i j}$ is, the greater the degree of dependency between $x_{i}$ and $F_{j}$ is [3].

\section{EMPIRICAL EVALUATION AND ANALYSIS OF INDUSTRIAL COMPETITIVENESS IN EASTERN PROVINCES AND CITIES}

The paper tests the applicability of the factor analysis based on the calculation of bartlett's sphericity test and KMO test. Bartlett's sphericity test shows that:

TABLE II. KMO AND BARTLETT'S TEST

\begin{tabular}{|c|c|c|}
\hline \multicolumn{2}{|c|}{ Kaiser-Meyer-Olkin Measure of Sampling Adequacy. } & 0.565 \\
\hline Bartlett's Test of Sphericity & Approx. Chi-Square & 229.321 \\
\hline & df & 55.000 \\
\hline & Sig. & 0.000 \\
\hline
\end{tabular}

Bartlett value is 229.321 , and $\mathrm{P}$ is close to 0 , if significance level is 0.01 , we don't think correlation matrix is the original hypothesis of a unit matrix, there is a significant difference between the correlation matrix and the unit matrix, so it is feasible to consider factor analysis. The value of KMO is 0.565 , so we can analyse the original index variables by the factor analysis.

\section{A. The main computing steps and results}

The table III shows that, according to the standards that eigenvalues of the correlation coefficient matrix is greater than 1 , three main factors can be extracted from 11 original statistical indicators. The accumulative total of variance of the three main factors reaches $95.83 \%$, which meets the requirements of the number of cumulative contribution rate of factor. 
TABLE III. TOTAL VARIANCE EXPLAINED

\begin{tabular}{c|c|c|c|c|c|c}
\hline \multirow{2}{*}{ Component } & \multicolumn{3}{|c|}{ Initial Eigenvalues } & \multicolumn{3}{c}{ Extraction Sums of Squared Loadings } \\
\cline { 2 - 7 } & Total & \% of Variance & Cumulative \% & Total & \% of Variance & Cumulative \% \\
\hline 1 & 7.042 & 64.017 & 64.017 & 7.042 & 64.017 & 64.017 \\
\hline 2 & 2.237 & 20.337 & 84.355 & 2.237 & 20.337 & 84.355 \\
\hline 3 & 1.262 & 11.476 & 95.830 & 1.262 & 11.476 & 95.830 \\
\hline 4 & 0.240 & 2.180 & 98.010 & & & \\
\hline
\end{tabular}

The factor 1 can be named as dominant industrial competitiveness, including the number of enterprises, industrial output, gross assets and profit, R\&D personnel of full-time equivalent, and the average number of all workers. The factor 2 can be named as potential industrial competitiveness, including $R \& D$ expenditure in the proportion of main business revenue and rate of the output value of new products. The factor 3 can be named competitiveness of industrial benefit, including the last of 11. We can draw the provincial and municipal industrial competitiveness ranking, according to the factor scores of provinces and cities, as shown in TableIV:

TABLE IV. PROVINCES AND CITIES FACTORS AND COMPREHENSIVE EVALUATION SCORE AND RANKING OF EASTERN PROVINCES INDUSTRIAL COMPETITIVENESS

\begin{tabular}{|c|c|c|c|c|c|c|c|c|}
\hline \multirow{2}{*}{ provinces } & \multicolumn{3}{|c|}{$\begin{array}{c}\text { Dominant } \\
\text { industrial } \\
\text { competitiveness }\end{array}$} & \multicolumn{2}{c|}{$\begin{array}{c}\text { Potential industrial } \\
\text { competitiveness }\end{array}$} & \multicolumn{2}{c|}{$\begin{array}{c}\text { Industrial benefit } \\
\text { competitiveness }\end{array}$} & \multicolumn{2}{c|}{$\begin{array}{c}\text { Comprehensive } \\
\text { industrial } \\
\text { competitiveness }\end{array}$} \\
\cline { 2 - 9 } & score & ranking & score & ranking & score & ranking & score & ranking \\
\hline Beijing & -0.8157 & 10 & 1.1499 & 3 & 0.5824 & 4 & -0.2312 & 8 \\
\hline Tianjin & -0.7606 & 9 & 1.3199 & 1 & 1.0928 & 1 & -0.0971 & 6 \\
\hline Hebei & -0.1245 & 6 & -1.6052 & 12 & 0.3449 & 8 & -0.3820 & 9 \\
\hline Liaoning & -0.0793 & 5 & -0.9357 & 10 & 0.4688 & 7 & -0.1951 & 7 \\
\hline Shanghai & -0.4589 & 7 & 1.2634 & 2 & 0.5462 & 5 & 0.0269 & 5 \\
\hline Jiangsu & 1.7282 & 1 & -0.1653 & 7 & 0.4758 & 6 & 1.1765 & 1 \\
\hline Zhejiang & 0.4390 & 4 & 0.4988 & 5 & -0.8533 & 9 & 0.2966 & 4 \\
\hline Fujian & -0.4802 & 8 & -0.0036 & 6 & -1.2070 & 11 & -0.4664 & 10 \\
\hline Shangdong & 1.3144 & 3 & -0.4921 & 8 & 0.8000 & 3 & 0.8697 & 3 \\
\hline Guangdong & 1.4175 & 2 & 0.7360 & 4 & -1.1680 & 10 & 0.9628 & 2 \\
\hline Guangxi & -1.1023 & 12 & -0.5171 & 9 & -1.9248 & 12 & -1.0769 & 12 \\
\hline Hainan & -1.0778 & 11 & -1.2490 & 11 & 0.8422 & 2 & -0.8837 & 11 \\
\hline
\end{tabular}

\section{B. Comprehensive Evaluation and Analysis}

Industrial competitiveness of the 12 provinces in eastern is divided into three categories, according to clustering analysis, the results are as follows:

\begin{tabular}{l|l}
\hline \multicolumn{1}{c|}{ categories } & \multicolumn{1}{c}{ provinces } \\
\hline The stronger industrial competitiveness & Jiangsu, Guangdong, Shandong \\
\hline The strong industrial competitiveness & Zhejiang, Shanghai, Tianjin, Liaoning, Beijing \\
\hline The weak industrial competitiveness & Hebei, Fujian, Hainan, Guangxi \\
\hline
\end{tabular}

1) In general, the distribution of industrial competitiveness in eastern region is equilibrium.In the table IV, the average score of industrial competitiveness in eastern is 0 the poor score is 2.25 . In 12 provinces and cities, five provinces and cities's score is above the average---Shanghai, Jiangsu, Zhejiang, Shandong and Guangdong, including Jiangsu whose score is more than 1 , and much higher than the average; there are seven provinces whose score is below the average--Beijing, Tianjin, Hebei, Liaoning, Fujian, Guangxi and Hainan. Guangxi and Hainan score lower than -0.5.Obviously, the scores of industrial competitiveness of the 12 provinces and cities basically evenly distribute on both sides of the mean.

2) In the spatial distribution, industrial competitiveness of the south provinces and cities is higher than the 
north .Provinces whose industrial competitiveness is the strongest is Jiangsu, Guangdong, Shandong, with the averaged of 1.003, have an advantage in foundation and the overall strength, especially the dominant industrial competitiveness. There are provinces whose industrial competitiveness is the stronger --- Zhejiang, Shanghai, Tianjin, Liaoning, Beijing, the average score is -0.04 , Liaoning except, the rest has a strong competitiveness in the potential industrial competitiveness and industrial benefit competitiveness, especially Beijing and Tanjin with great potential for development; Industrial competitiveness is strong in Hebei, Fujian, Hainan, Guangxi. From a regional distribution point of view: the top three provinces and municipalities, south of the two, namely,Guangdong and Jiangsu. Competitiveness in the top six provinces and municipalities, south of the four, namely, Guangdong, Jiangsu, Zhejiang and Shanghai. And the average score of the top three provinces or cities is 1.003 , and much higher than the overall average score. This presents a geographical distribution of industrial competitiveness that industrial competitiveness of the south provinces and cities is higher than the north and the gap between the provinces is big.

3) From the factor comparison, industry profitability in the eastern provinces is not high, and the potential development is insufficient. Something can be obtained from tableIV: there are six provinces and cities of 12 in the dominant industrial competitiveness ranking higher than the overall competitiveness ranking, flat one, lower five; six provinces and cities's potential industrial competitiveness is higher than the overall competitiveness, flat one, and lower five; there exist 4 provinces and cities with industrial benefit competitiveness rank higher than the comprehensive competitiveness, three of them are flat and lower five; there are 6 provinces and cities whose dominant industrial competitiveness's score rank higher than the potential industrial competitiveness, flat one, and lower five. Those show that potential industrial competitiveness in the eastern provinces is not enough, the industrial enterprises do not attach enough importance to scientific research, and economic efficiency is not high, and lack of development potential, which will be bad to further improve the comprehensive competitiveness and the sustainable development of economy.

\section{CONCLUSIONS AND RECOMMENDATIONS}

Something we can see from factor analysis that the results of the 12 provinces in the industrial competitiveness of three factors on strength, in order to improving industrial competitiveness of provinces, we should strengthen the construction of industry in the above three aspects. And in order to do this, it must be needed to optimize industrial structure, and improve the level of the industry, only in this way can we enhance the industrial competitiveness in eastern, and increase the overall level of industrial competitiveness of China.

A. The industrial competitiveness of eastern provinces and cities presents the distribution that the Southern region is high and the northern region is low.This kind of situation is against industrial development of the eastern region the long run, improvement of industrial competitiveness. Therefore, various government departments should actively formulate principles and policies conducive to the development of industrial enterprises, improve the economic regulation, and create a kind of comfortable macro-environment for industrial development; the companies should actively promote internal reform, and draw lessons from the world advanced industrial enterprise management experience and development model, to make their own development strategies.

B. Jiangsu, Guangdong and Shandong should make full use of their competitive advantage, accelerate the process of informationization and modernization, focus on developing high technical content, high value-added products, and participate in international competition; At the same time, they can strengthen the cooperation with other provinces in eastern, drive the development of provincial industry, and promote further industrial competitiveness in eastern region ,through the output of elements such as talent, capital, technology .

C. The areas with weak industrial competitiveness such as, Hebei, Fujian, Hainan, Guangxi ,should make efforts to create a good investment environment, on the one hand, vigorously introduce the foreign capital, technology and equipment; on the other hand, absorb the folk investment, improve the level of enterprise technology, and enhance the industrial competitiveness.

D. We should actively promote the development of high and new technology industry In the whole east, optimize the structure of R \& D resources, and gradually increase the role of $\mathrm{R} \& \mathrm{D}$ in industrial competitiveness. Provincial high and new technology industry is booming at present, science and technology investment increased year by year, the industrial enterprises have gradually become the main body of $R \& D$ activities, the provinces should cultivate a batch of strong strength and competitiveness of industry and the "leading enterprise" on the basis of their own advantages and local characteristics, and form its own competitive advantage[4].

\section{REFERENCES}

[1] WEI Hou-kai, and WU Li-xue, "Evaluation of Regional Industrial Competitiveness in China", China Industrial Economy, Vol. 39, No. 11, pp. 54-62, Nov. 2010. (references)

[2] Li-ming, and Huang Shan-yan, "Statistical Evaluation of Chengdu Industrial Competitiveness ", Statistics and Decision, Vol. 34, No. 18 pp. 132-135, Sep. 2011.(references)

[3] Chen-hong. B. Author, "Research on Henan province industrial competitiveness", Henan Social ,Vol. 18, No. 2, pp. 213-216, Mar. 2010. (references)

[4] Chen-Lizhen, Chen-Haibo, "The Comparison of City of Jiangsu Province Industrial Competitiveness ", Statistics and Decision, Vol. 10, No. 166, pp. 50-51, Oct. 2003.(references) 